\title{
PLC Human Machine-Interfaces Based System for Vietnam Drip Coffee Maker Application
}

\author{
Nur Alif Mardiyah ${ }^{\star 1}$, A. Hakam Sudrajat ${ }^{2}$, Amrul Faruq ${ }^{3}$ \\ 1,2,3 Universitas Muhammadiyah Malang \\ diyahsyk@gmail.com*
}

\begin{abstract}
The most recent development of digital technology is rapidly growing having a strong impact in daily activities. Automation is a trend in society to make those activities become easier. Moreover, efficiency has played the main role in the automation concept. For example, when making a drink which requires to accurately mix all required ingredients, like sugar, tea, and also coffee, the process may take time. Meanwhile, other more important processes have waited to be carried out. The idea of fasten up these activities may be preferable, exemplified by making an automatic drink maker machine. Moreover, coffee has been popular drink fancied by most people on the society. Hence, due to the high load of the people's activity, everything is required to be instant and efficient. According to this trend, to provide an efficient, easy, and good management, we need to create an automatic, fast, and accurate system control which can be implemented by using Programmable Logic Controller (PLC) and Human-Machine Interface (HMI). Meanwhile, in this research, Omron PLC and HMI are utilized to build an automatic drink maker device of Vietnamese Drip Coffee designed to resolve the society's needs of coffee with higher efficiency of serving process. The automatic coffee maker device of Vietnamese Drip Coffee based on PLC and HMI is a device designed to simplify the making process of Vietnamese Drip Coffee in hot condition. This device can be operated by only touching/tapping on its coffee menu choices. The design of this device has the main purpose to operate and test the control system based on PLC and HMI to control and monitoring the automatic process of producing Vietnamese Drip Coffee started from choosing the coffee types until mixing process.
\end{abstract}

Keywords: Human-Machine Interface, Programmable Logic Controller, Vietnam Drip, Application Software

\section{Introduction}

The rapid development of digital technology nowadays has greatly influenced modern lifestyle. Automation offers beneficial outcomes to ease diverse human activities by providing efficiency and effectiveness as the main role in the automation concept. Microcontroller [1] is one of the examples of digital devices utilized for automatic controlling.

For example, drink serving processes can provide intricate processes in appropriately preparing and processing all required ingredients; moreover, this drink making process may also need some period of time that can be more efficiently reduced to give a way to other more important activities. Thus, some inventions such as an automatic drink maker machine employed an automatic programed controlling may suit this need. A microcontroller is needed to perform some commands using machine language program like assembly and Visual Basic 6.0.

Most people in many different societies have been familiar with their coffee drinking habit. Moreover, this drink may be inseparable to their daily activities in various places. Therefore, finding more instant and efficient method of coffee serving process can be indispensable to improve the overall job performance of a worker or an institution. Therefore, a coffee maker machine utilizing a microcontroller is designed to overcome the people's needs of coffee with more efficient process [2] [3]. This machine is intended for use in the offices, coffee shop, mini market and supermarkets.

In the operation of equipment or an electrical machine, sometimes we find various obstacles because of the arrangement or controlling processes. According to that, to reach an efficient, easy, and good management, creating an automatic, fast, and accurate system control will be needed. Therefore, the utilization of Programmable Logic Controller (PLC) and HumanMachine Interface (HMI) will be properly implemented.

Mardiyah, N., Sudrajat, A., \& Faruq, A. (2017). PLC Human Machine Interfaces-based system for Vietnam Drip Coffee Maker Application. Kinetik : Game Technology, Information System, Computer Network, Computing, Electronics, and Control, 3(1). http://dx.doi.org/10.22219/kinetik.v3i1.272 
PLC has been widely used in various applications to replace relay function; moreover, its application is often found in the processes in industrial, automobile, and manufacture area. By utilizing PLC, the complexity and complicated control process can be executed by the integrity of Personal Computer (PC) with various control systems like PLC in the automation world. It has eased the monitoring and controlling functions. Meanwhile, HMl works within the scope of Supervision Control and Data Acquisition (SCADA) controlling wide area at remote locations and performing supervision function on master location and Remote Terminal Unit (RTU) on data collector. Furthermore, SCADA can perform automatic control by a controller and manual controller operated by an operator using controlling process through HMI [4].

In this study, Omron PLC and HMI were used to build an automatic drink maker device of Vietnamese Drip Coffee; in addition, this device is designed to resolve the society's needs of having more efficient coffee serving process [5] [6] [7]. The inputs of this machine are coffee medium-sized powder, sweet liquid chocolate, sweetened condensed milk and hot water having a temperature of $90^{\circ} \mathrm{C}$ to $96^{\circ} \mathrm{C}$. Hence, these ingredients can be processed into several types of beverages being able to be selected with coffee as its basic ingredients.

The automatic drink maker device of Vietnamese Drip Coffee based on PLC and HMI is a device designed to simplify the making process of serving hot Vietnamese coffee. Additionally, this device can automatically be operated by only touching on one of the coffee selections displayed on the menu choice. After few moments, the selected coffee will be ready, and the consumer can enjoy the coffee of his choice [8] [9] [10].

In another process, this process may involve some works related to mixing variations of coffee flavors, brewing to stirring coffee in a glass located on the conveyor passing through its path and will stop at predetermined places.

The design of this device has the main purpose to perform and test the control system based on PLC and $\mathrm{HMI}$, in controlling and monitoring the automatic process of producing Vietnamese drip coffee started from choosing desired coffee on the menu until mixing all necessary ingredients based on the user's selection.

\section{Research Method}

In this stage, the design creation and system manufacture were implemented by making a block diagram of the system, determining and arranging algorithms for software design as presented in Figure 1. HMI used in this system presented in Figure. 2 is HMI OMRON NB7WTW00B. Furthermore, Figure 2 illustrates the application of a 24 VDC power supply, PC connection to HMI using USB slave terminal, and HMI connection to PLC using RS232 9 pin cable.

In designing HMI layout, there are 3 main menus and 1 emergency button: (a) Chocolate coffee, automatically processed by the machine in the making of chocolate coffee; (b) Milk coffee, automatically serving users who want to have coffee milk; (c) Original coffee, serving original coffee to the users; and (d) Emergency button, stopping the process in case of system errors.

The menu screen display shows some of the conditions during the process. Moreover, it also provides some additional features to facilitate system/machine checking functions. For example, the opening or closing valve, the running or stopping conveyor and the monitoring brewing process. Figure 3 shows the layout design created using NB-Designer software.

Before executing programming, the most important operations to do are addressing and designing that will be used on PLC, the prepared addresses including PLC inputs and PLC outputs. The PLC used is Omron CPM2A-60CDR-A PLC with 36 inputs and 24 outputs. The inputs used have addresses of $0000-0011,0100-0111$, and $0200-0211$. Meanwhile, the outputs are assigned by addresses of $1000-1007,1100-1107$, and $1200-1207$.

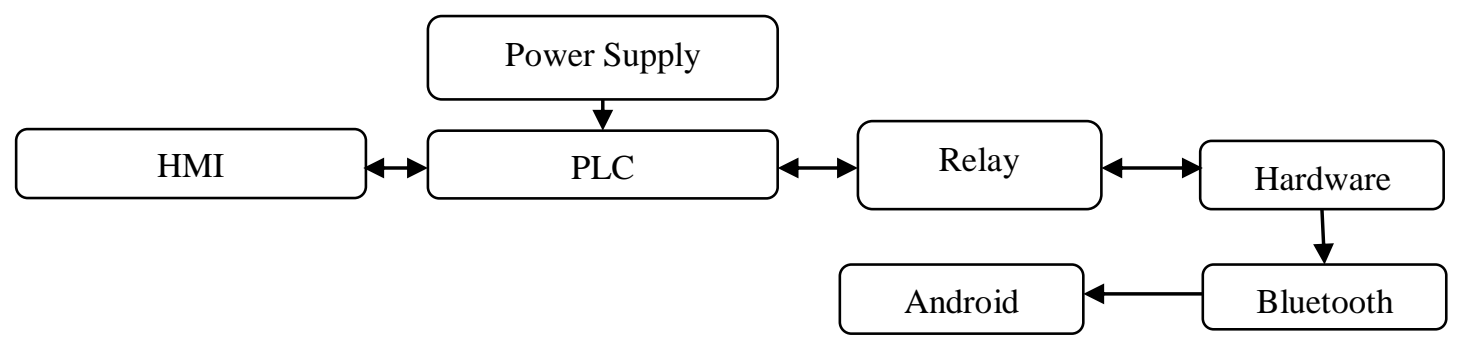

Figure 1. Block Diagram of Control and Monitor System 

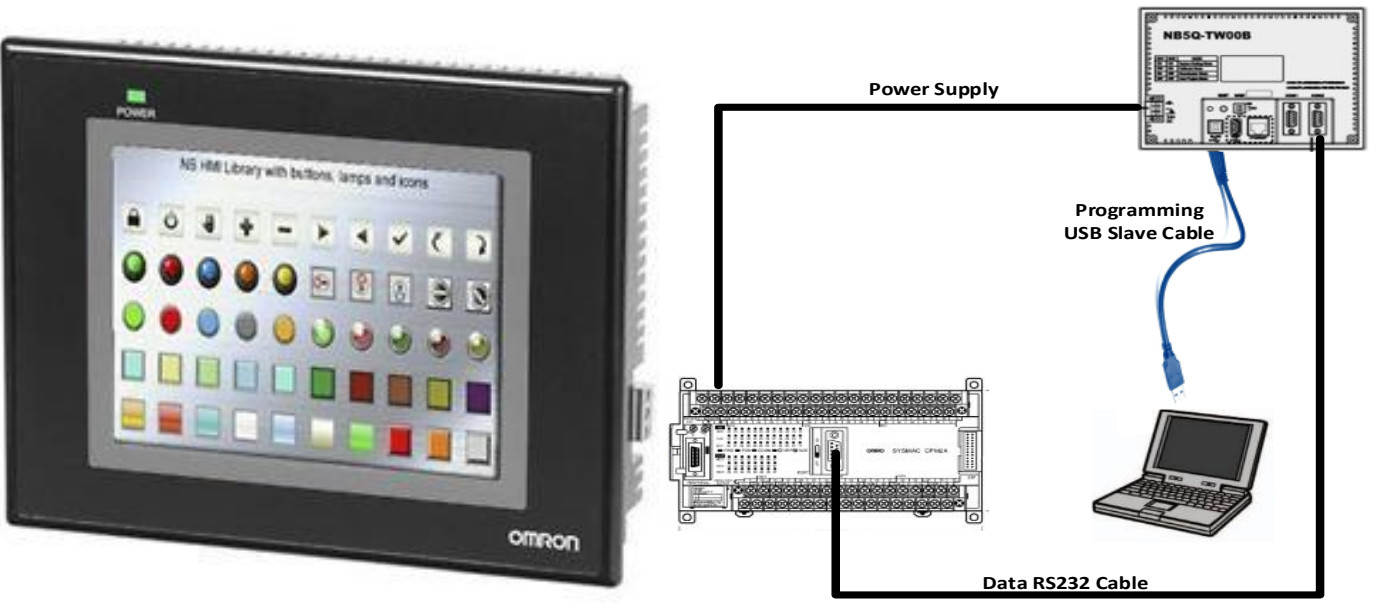

Figure 2. Hardware Connection of HMI Omron NB7W-TWOOB

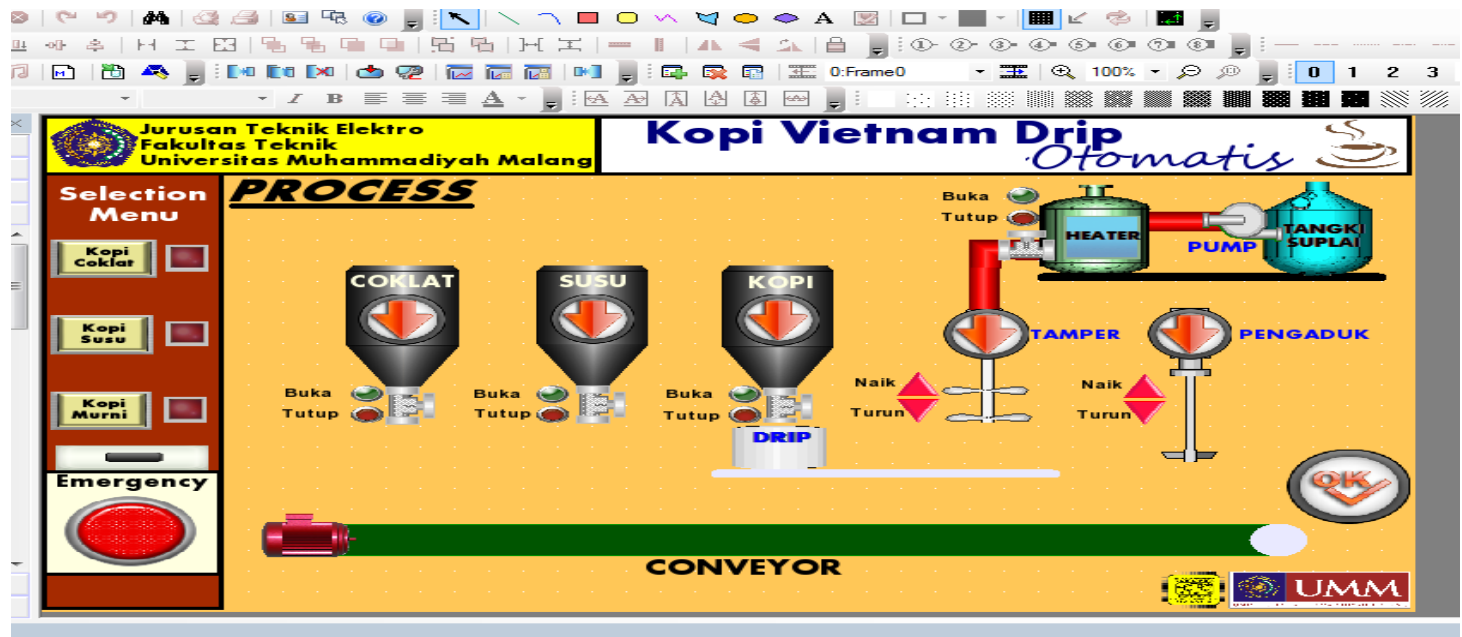

Figure 3. HMI Process

\section{Results and Discussion}

This chapter will discuss the examination based on the planning of the system created. System examination is completed by creating CX-Programmer and NB-Designer programs. This test was conducted to determine the reliability of the system and to determine whether the system was in accordance with the desired planning. At first, the examination was completed separately; afterwards, it was implemented into an integrated system. The realization included the following: (a) The examination of PLC program through CX-Programmer software; and (b) HMI program examination through NB-Designer software.

\subsection{PLC Program Using CX-Programmer Software}

After designing a ladder diagram, the following process was testing the program working system with OMRON CPM2A-60CDR-A PLC. This test was intended to test the conformity of the running program according to plan. Figure 4 illustrates the layout of the motor on the hardware operated with the PLC. Furthermore, Figure 5 presents the operating workflow of the original coffee process, employing a timer instruction in a sequential manner.

The emergency process examination employed the instruction format of one address input used to trigger all reset addresses RSET. One example is illustrated in Figure 6 related to the process of serving chocolate coffee. The input address 0.04 was enabled to trigger RSET 30.15 on; therefore, SET 30.15 was deactivated, completely stopping the process of serving chocolate coffee even though the chocolate coffee process has not yet finished. This mechanism was identically utilized on the process of serving original coffee and milk coffee. 


\subsection{Input and Output Configuration}

The address of PLC includes input and output PLC as illustrated in Table 1. The logic condition used in the device input is NO (Normally Open). Addresses of SET, RESET and COUNTER configurations are presented in Table 2.

\subsection{PLC Application Examination}

PLC application measured by CX-Programmer software on the process of making original coffee, coffee chocolate and coffee milk obtains the result of sequential operation process. Table 3 and the timing diagram of the data obtained from the PLC program experiment on the actuator are ON-condition (TRUE) during the process. In Table 3, the serving experiment of original coffee shows the condition of active M9 due to having active PLC program while serving original coffee. Therefore, it triggers $\mathrm{M} 9$ to be in active state.

HMI device used in this work is Omron NB7W-TW00B, and HMI programming utilizes NBDesigner software. This software is employed to create an image view on Omron $\mathrm{HMl}$ and specifies the address in PLC to be used. In the HMI view, there are three menu options, namely the coffee chocolate button, the milk coffee button, the original coffee button and the emergency button. The main display menu on $\mathrm{HMI}$ is depicted in Figure 7.

\subsubsection{Original Coffee Button}

In the NB-Designer software, the original coffee button uses a component called bit state setting. This component is used to determine the touch area of the screen. It also sets the addressing on the PLC to get the ON or OFF conditions when this area is touched. In Figure 8, the basic attributes of the write address section provide the option of setting the address to be given the ON or OFF status of the button exemplified by the original coffee button, having area or address variable of $\mathrm{CIO} I \mathrm{IR}$ bit with address number 0.02 .

In Figure 8, the bit state setting offers the option of setting the function keys when touched. If ON is selected, then the data bits in the address will be located ON condition. If OFF is selected, then the data bits at the destination address will be OFF. If TOGGLE is selected, then the data bits in the destination address will change. If RESET is selected, the data bits in the destination address will be ON as long as the screen is touched. In Figure 9, the text settings are employed according to the bit status CIO_IR_bit of the address number 0.02. Furthermore, they are also used to perform graphical settings to display the status of the bit CIO_IR bit of the address number 0.02 and to adjust the button shapes or designs. Figure 10 presents the application of the security settings and notifications; in addition, it also shows the position the touch area. In the NB-Designer software, the indicator light is created using bit state lamp, displaying the bit status of a particular address. If the status is bit 0 , then the status graph 0 will be displayed, so if status is bit 1 then the status graph will be 1 as illustrated in Figure 11.

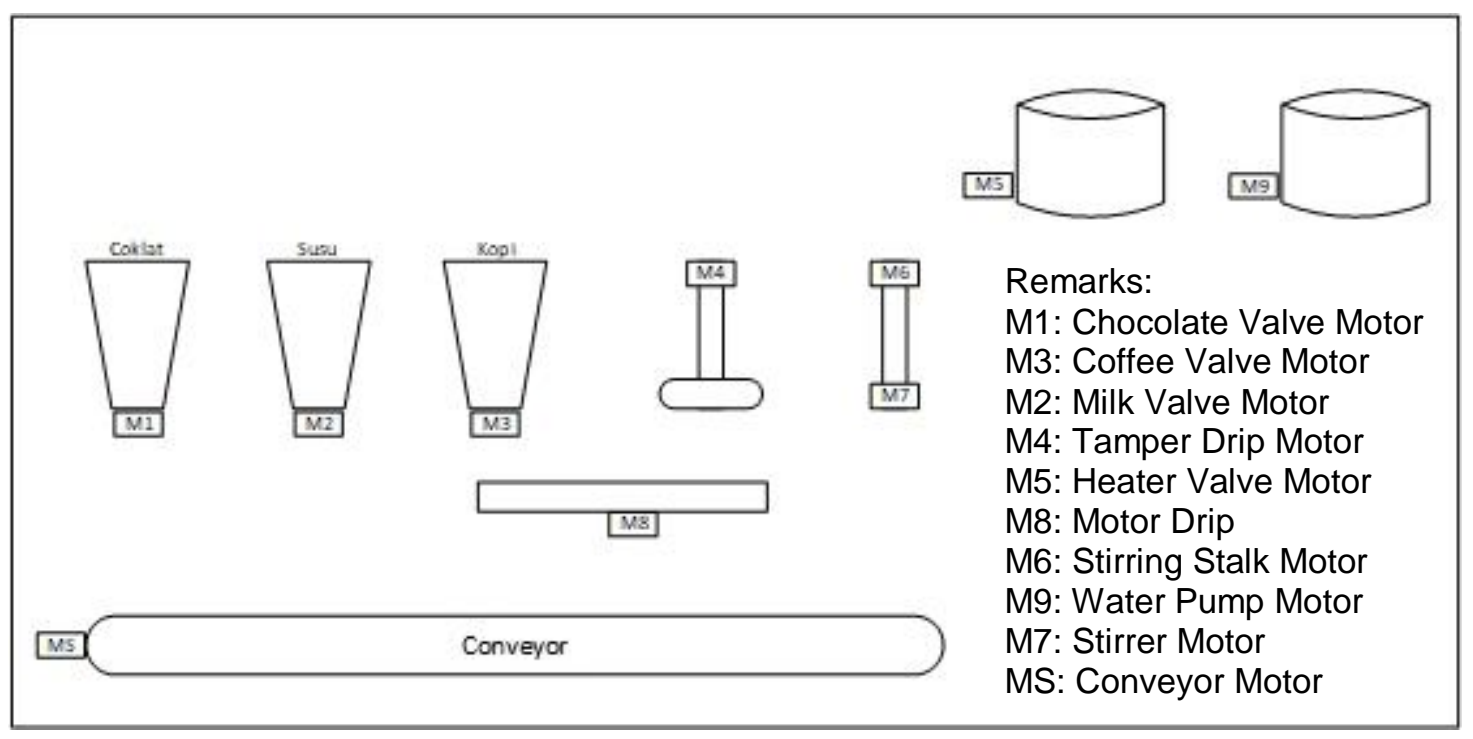

Figure 4. The Motor Layout

KINETIK Vol. 3, No. 1, February 2018: 35-44 


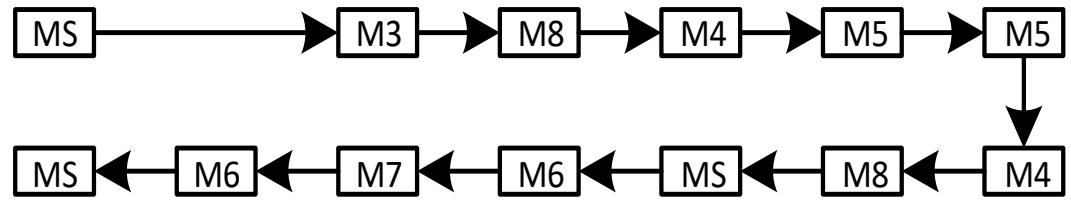

Figure 5. The Process Flow of Serving Original Coffee

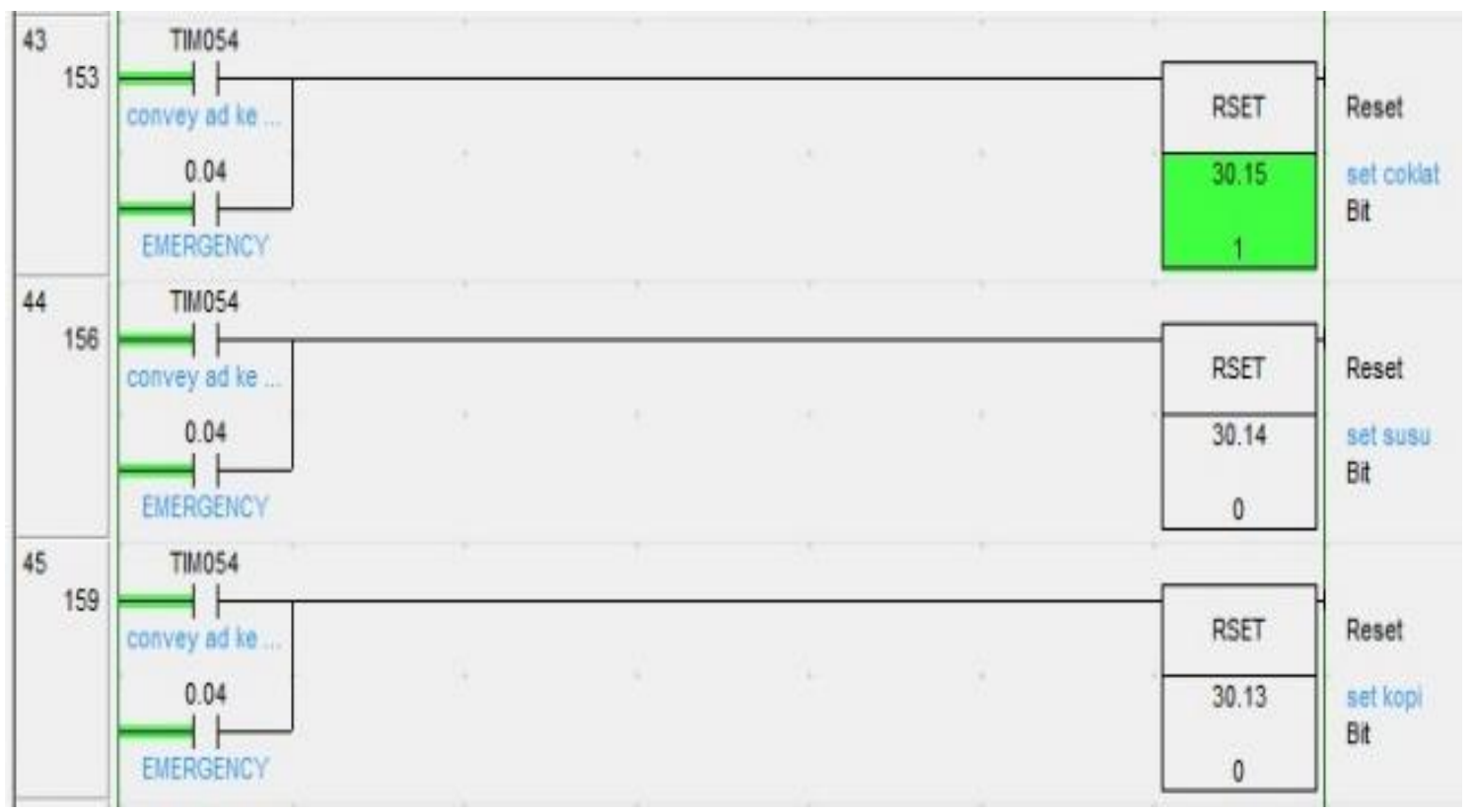

Figure 6. Ladder Diagram Instructions of Emergency Input Address 0.04

Table 1. Address of Input and Output PLC

\begin{tabular}{cccc}
\hline \multirow{2}{*}{ No } & \multicolumn{2}{c}{ l/O Address } & Remarks \\
\cline { 2 - 3 } & Input & Output & Chocolate \\
\hline 1 & 0.00 & & Milk \\
2 & 0.01 & & Coffee \\
3 & 0.02 & & Emergency/Warning \\
4 & 0.04 & 10.00 & Conveyor \\
5 & - & 10.01 & M1 Open \\
6 & - & 10.02 & M1 Close \\
7 & - & 12.00 & M2 Open \\
8 & - & 12.01 & M2 Close \\
9 & - & 10.03 & M3 Open \\
10 & - & 10.04 & M3 Close \\
11 & - & 10.05 & M8 Right Side \\
12 & - & 10.06 & M8 Left Side \\
13 & - & 11.00 & M4 Slow-down \\
14 & - & 11.01 & M4 Top-up \\
15 & - & 11.02 & M5 Open \\
16 & - & 11.03 & M5 Close \\
17 & - & 11.04 & M6 Slow-down \\
18 & - & 11.05 & M6 Top-up \\
19 & - & 11.06 & M7 \\
20 & - & 12.02 & M9 \\
21 & - & &
\end{tabular}




\begin{tabular}{ccccc}
\multicolumn{5}{c}{ Table 2. Address of SET-RSET and COUNTER } \\
\cline { 2 - 4 } No & \multicolumn{3}{c}{ Address } & \multirow{2}{*}{ Remarks } \\
\cline { 2 - 4 } & SET & RSET & COUNTER & \\
\hline 1 & 30.15 & 30.15 & - & Chocolate Set-up \\
2 & 30.14 & 30.14 & - & Milk Set-up \\
3 & 30.13 & 30.13 & - & Coffee Set-up \\
4 & 30.12 & 30.12 & - & M1 HMl Set-up \\
5 & 30.10 & 30.10 & - & M3 HMl Set-up \\
6 & 30.09 & 30.09 & - & M8 HMl Set-up \\
7 & 30.08 & 30.08 & - & M4 HMI Set-up \\
8 & 30.07 & 30.07 & - & M5 HMI Set-up \\
9 & 30.06 & 30.06 & - & M6 HMI Set-up \\
10 & 30.05 & 30.05 & - & HMl OK Set-up \\
11 & 30.11 & 30.11 & - & M2 HMI Set-up \\
12 & - & - & 070 & Chocolate Set-up \\
\hline
\end{tabular}

Table 3. Actuator Data ON-condition (TRUE = 1)

\begin{tabular}{|c|c|c|c|c|c|c|c|c|}
\hline Examination & Motor & Open & Close & Motor-Up & $\begin{array}{l}\text { Motor- } \\
\text { Down }\end{array}$ & Right & Left & Active \\
\hline \multirow{10}{*}{$\begin{array}{l}\text { Original } \\
\text { Coffee }\end{array}$} & M1 & 0 & 0 & 0 & 0 & 0 & 0 & 0 \\
\hline & M2 & 0 & 0 & 0 & 0 & 0 & 0 & 0 \\
\hline & M3 & 1 & 1 & 0 & 0 & 0 & 0 & 0 \\
\hline & M4 & 0 & 0 & 1 & 1 & 0 & 0 & 0 \\
\hline & M5 & 1 & 1 & 0 & 0 & 0 & 0 & 0 \\
\hline & M6 & 0 & 0 & 1 & 1 & 0 & 0 & 0 \\
\hline & M7 & 0 & 0 & 0 & 0 & 0 & 0 & 1 \\
\hline & M8 & 0 & 0 & 0 & 0 & 1 & 1 & 0 \\
\hline & M9 & 0 & 0 & 0 & 0 & 0 & 0 & 1 \\
\hline & MS & 0 & 0 & 0 & 0 & 0 & 0 & 1 \\
\hline \multirow{10}{*}{$\begin{array}{c}\text { Chocolate } \\
\text { Coffee }\end{array}$} & M1 & 1 & 1 & 0 & 0 & 0 & 0 & 0 \\
\hline & M2 & 0 & 0 & 0 & 0 & 0 & 0 & 0 \\
\hline & M3 & 1 & 1 & 0 & 0 & 0 & 0 & 0 \\
\hline & M4 & 0 & 0 & 1 & 1 & 0 & 0 & 0 \\
\hline & M5 & 1 & 1 & 0 & 0 & 0 & 0 & 0 \\
\hline & M6 & 0 & 0 & 1 & 1 & 0 & 0 & 0 \\
\hline & M7 & 0 & 0 & 0 & 0 & 0 & 0 & 1 \\
\hline & M8 & 0 & 0 & 0 & 0 & 1 & 1 & 0 \\
\hline & M9 & 0 & 0 & 0 & 0 & 0 & 0 & 0 \\
\hline & MS & 0 & 0 & 0 & 0 & 0 & 0 & 1 \\
\hline \multirow{10}{*}{ Milk Coffee } & M1 & 0 & 0 & 0 & 0 & 0 & 0 & 0 \\
\hline & M2 & 1 & 1 & 0 & 0 & 0 & 0 & 0 \\
\hline & M3 & 1 & 1 & 0 & 0 & 0 & 0 & 0 \\
\hline & M4 & 0 & 0 & 1 & 1 & 0 & 0 & 0 \\
\hline & M5 & 1 & 1 & 0 & 0 & 0 & 0 & 0 \\
\hline & M6 & 0 & 0 & 1 & 1 & 0 & 0 & 0 \\
\hline & M7 & 0 & 0 & 0 & 0 & 0 & 0 & 1 \\
\hline & M8 & 0 & 0 & 0 & 0 & 1 & 1 & 0 \\
\hline & M9 & 0 & 0 & 0 & 0 & 0 & 0 & 0 \\
\hline & MS & 0 & 0 & 0 & 0 & 0 & 0 & 1 \\
\hline
\end{tabular}

\subsubsection{Original Coffee Process Examination on HMI}

The visual indicator on HMI will display the motor when being active. Figure 12 shows the results of $\mathrm{HMI}$ visual examination of original coffee process. In Figure 12, the original coffee indicator, motor and conveyor light up after the original coffee button is pressed. Afterwards, the indicator valve on the coffee is on, indicating that the process of the tool is on the filling of coffee. In Figure 13, the tamper indicator on the coffee lights up indicating the tool process is in the drip

KINETIK Vol. 3, No. 1, February 2018: 35-44 
process, and the tamper indicator on the coffee is on and the valve heater is lit in the OPEN position, indicating that the tool process is in the drip process and filled with heated water.

In Figure 14, the stirring process indicator lights up, and the indicator goes on, indicating that the tool process is in the stirring process. Furthermore, the conveyor and pump indicators are active, indicating that the process of the tool is charging water to the heater. In Figure 15, the OK indicator is active while the coffee button indicator is off, indicating that the process of making original coffee has been completed.

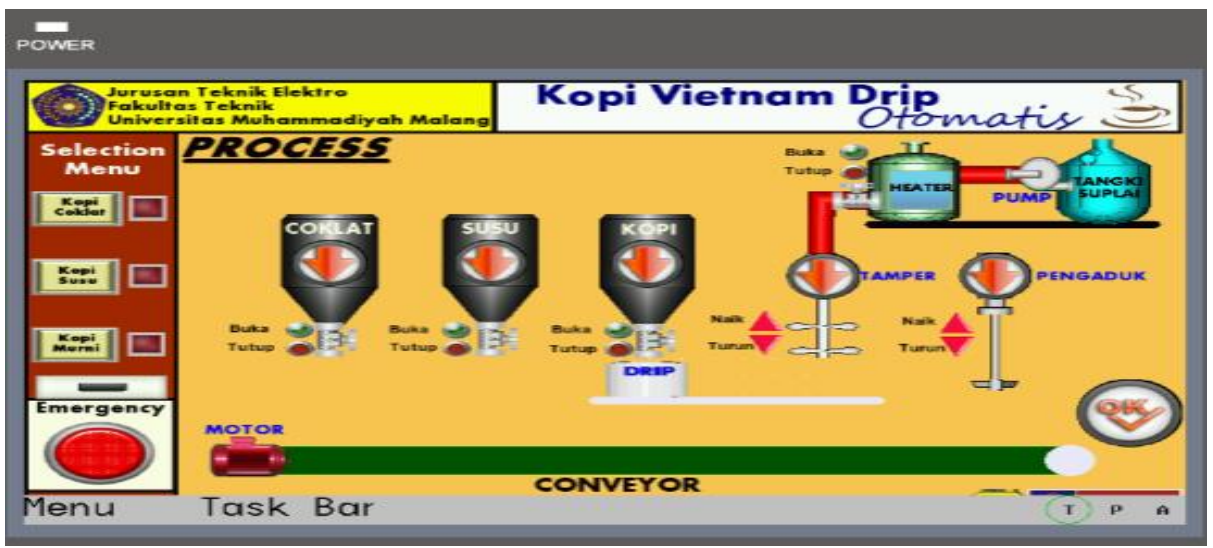

Figure 7. The First Menu Interface

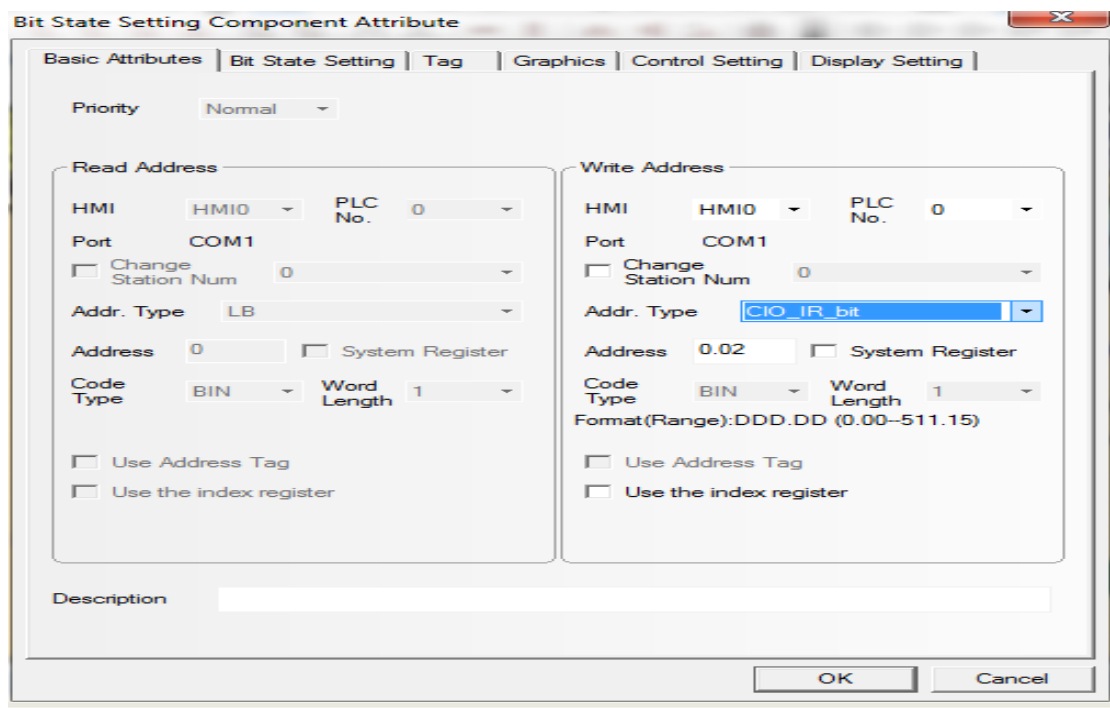

Figure 8. Sub-basic of Bit State Attributes

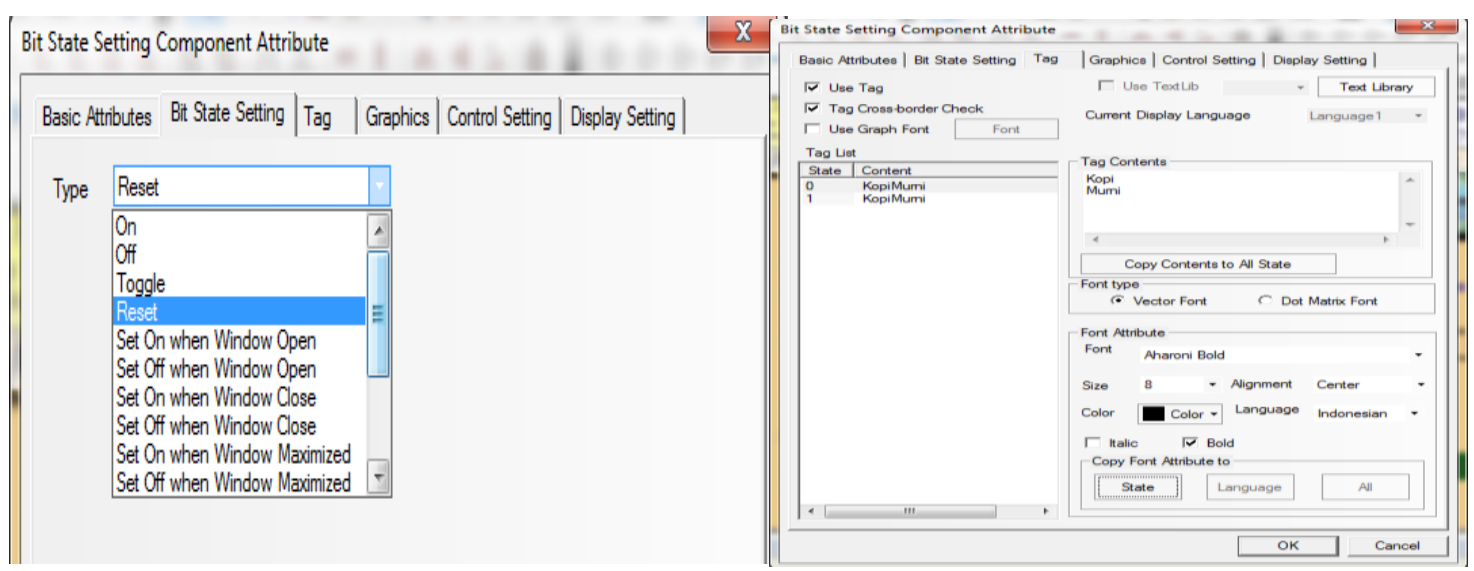

Figure 9. Sub-Bit State Setting and Sub-Tag 


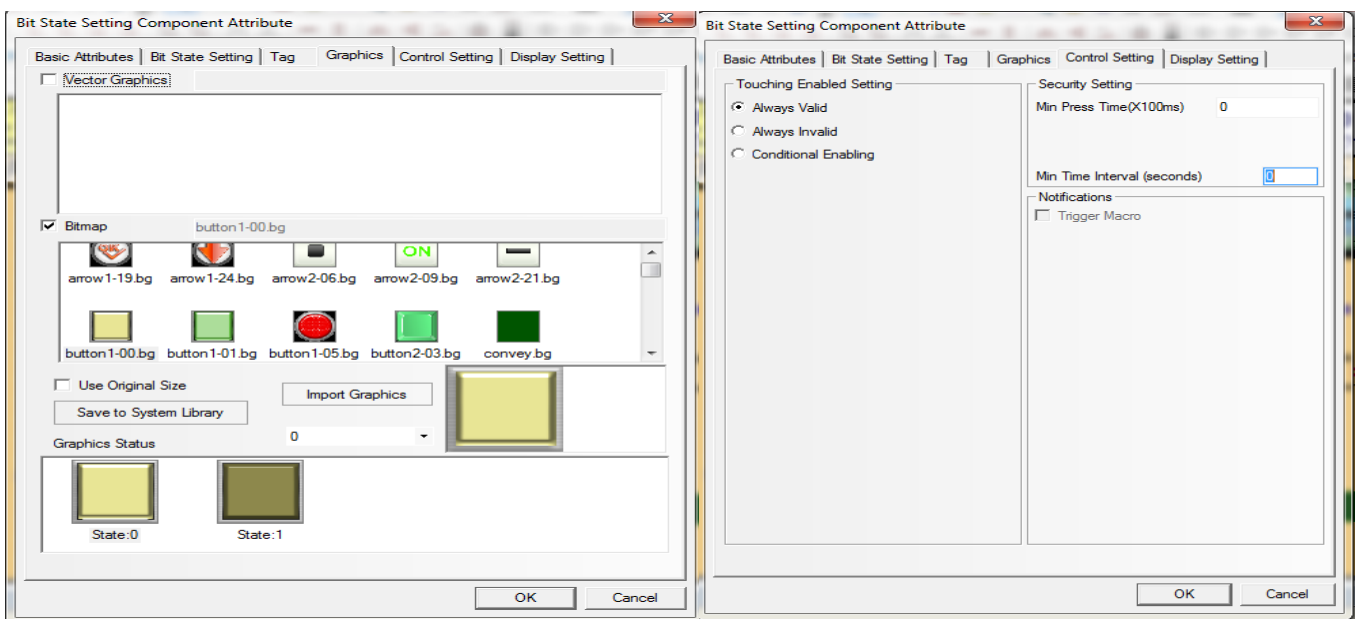

Figure 10. Sub-graphics of Sub-control Setting

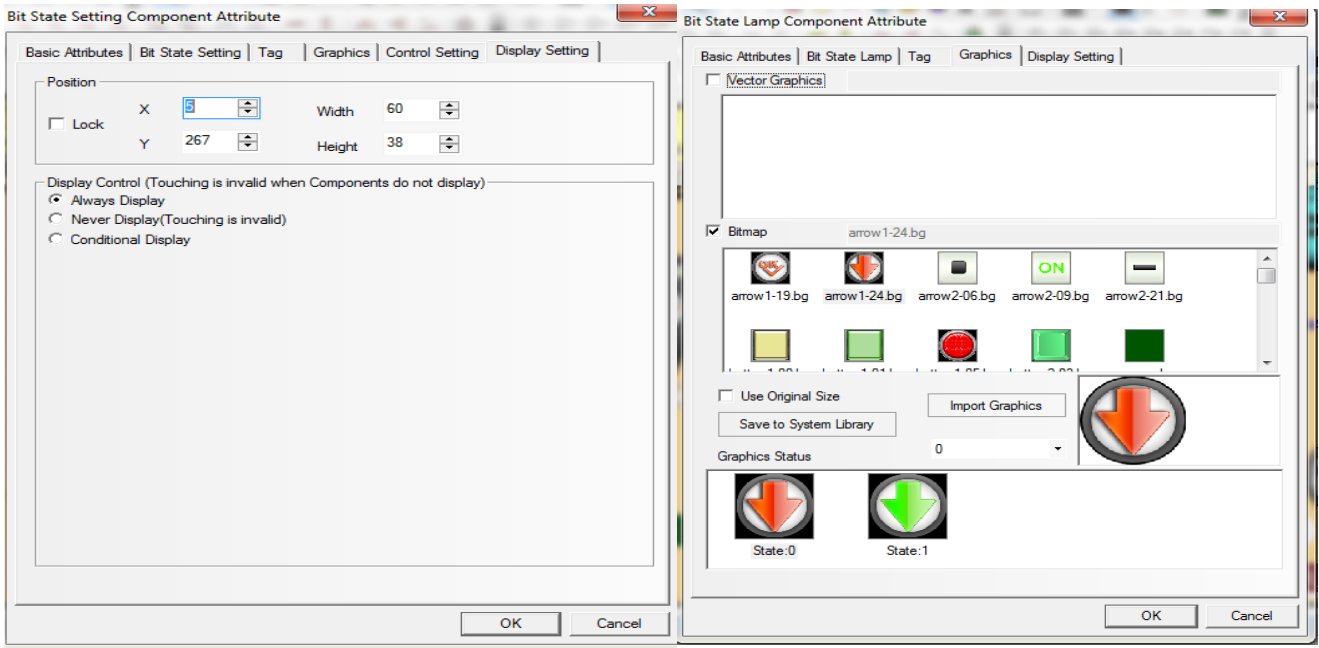

Figure 11. Sub-display setting of Bit State Lamp - Sub-graphics

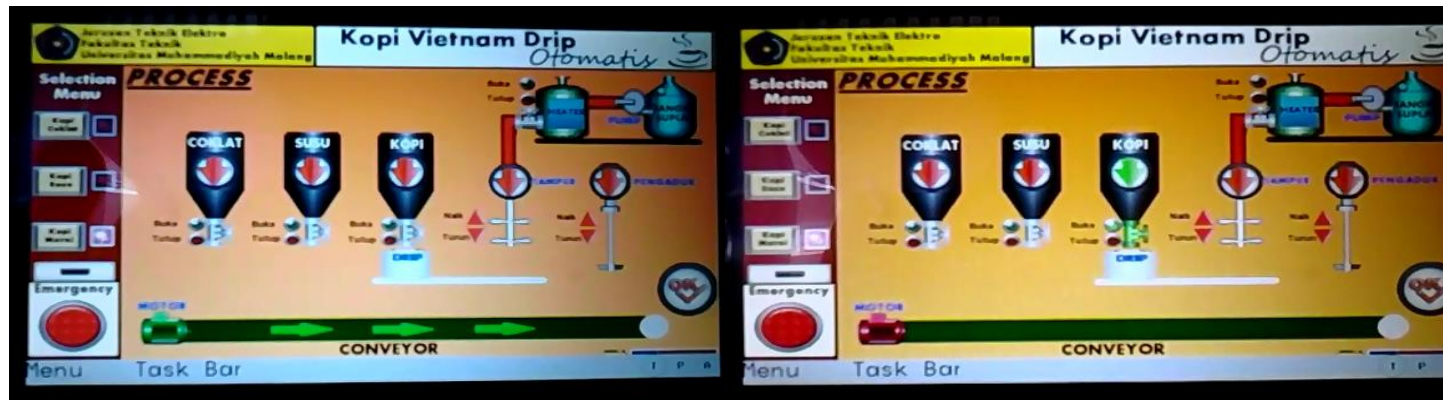

Figure 12. The Original Coffee Indicator and Active Conveyor

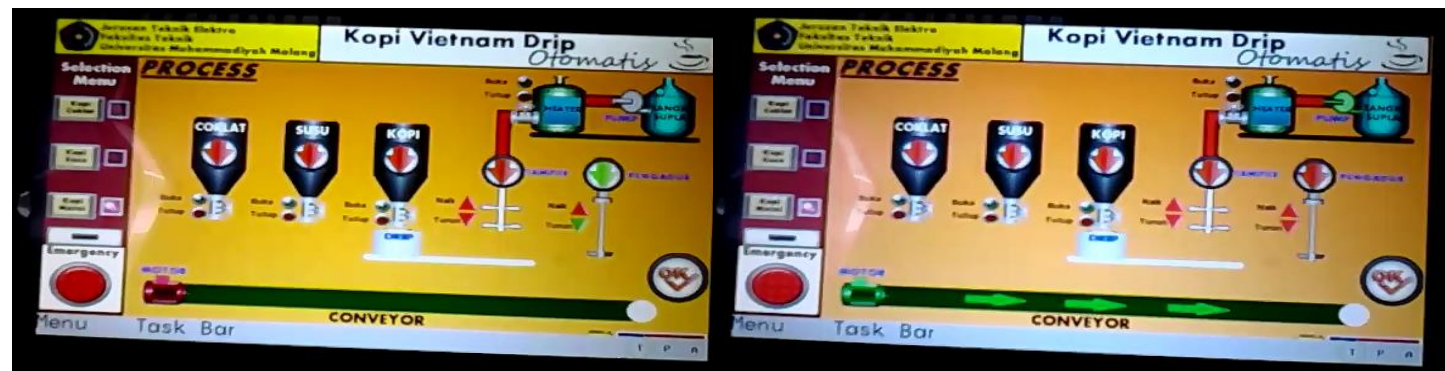

Figure 13. Tamper Drip Active

KINETIK Vol. 3, No. 1, February 2018: 35-44 


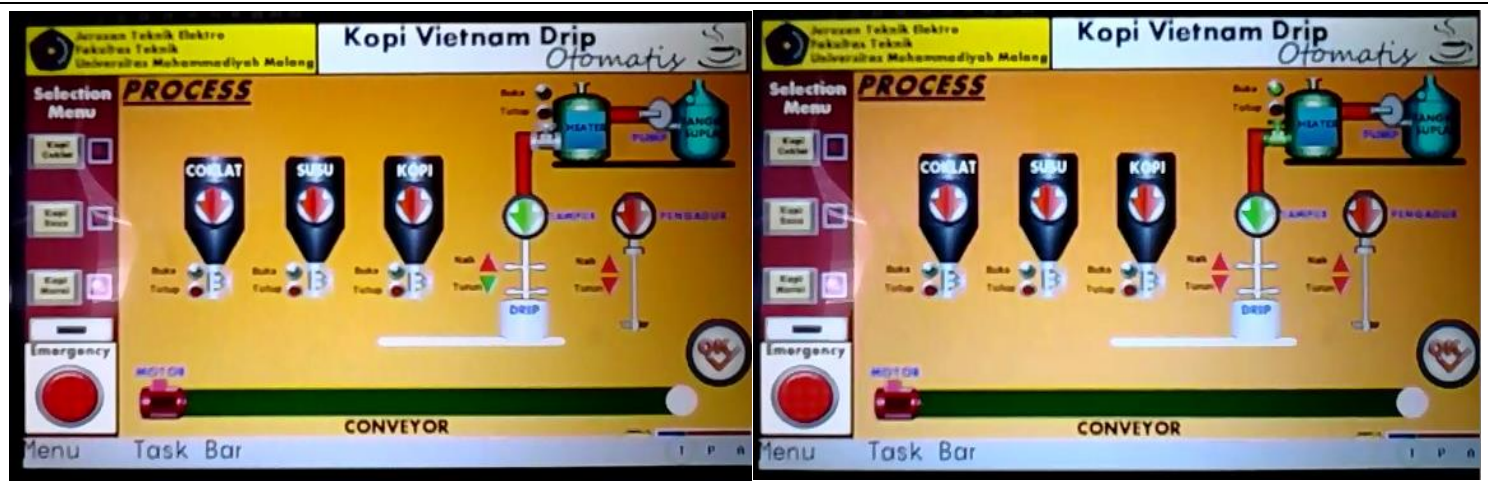

Figure 14. Active Stirring Process

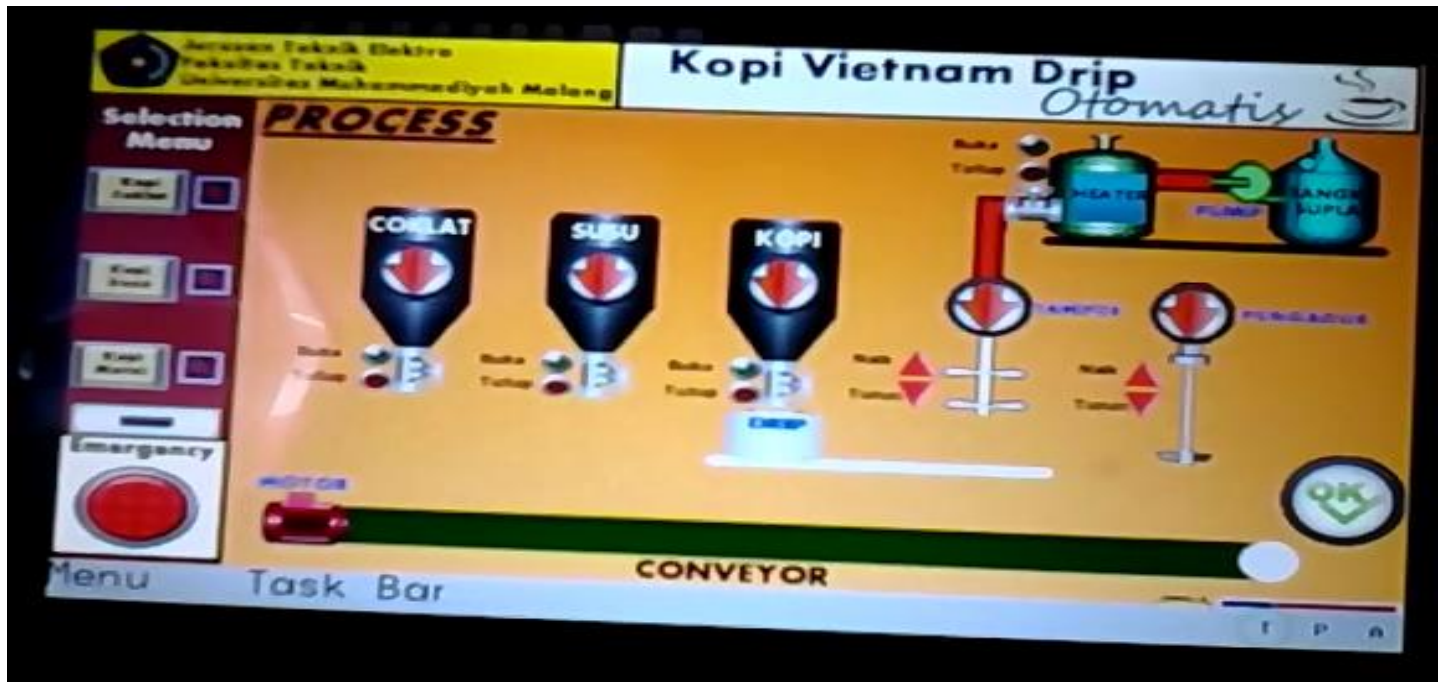

\section{Conclusion}

Figure 15. Active OK Indicator

After measuring PLC and HMI by using CX-Programmer software and NB-Designer software on Vietnamese Drip Coffee process, it can be concluded that the program to control the automatic coffee maker using PLC and HMI has been successfully implemented and utilized in the process of selecting chocolate coffee, milk coffee, and original coffee. The automatic coffee maker program produces a monitoring system of the process of serving chocolate coffee, milk coffee, and original coffee from the material to finish. The program settings on HMI and PLC can communicate and exchange data between the system and the synchronized HMI.

An embedded technologies and real-time analysis, monitoring, advanced control and predictive maintenance using LabVIEW [11] to add in existing PLC in this work can be addressed as the future work. LabVIEW has capabilities to design an advance control, improving distributed management system and new targets for Human-Machine Interfaces (HMIs).

\section{References}

[1] Yenni, H., and Ridwan, M., "Implementation of Microcontroller Setting ATMega8535 on an Automatic Coffee Maker," Journals of Education and Information Research (JEPIN), Vol.1, No.2, 2015.

[2] Umi, T., Ginta, P. W., and Septohadi, M., "Design of Automatic Coffee Maker Machine Using Microcontroller Mcs51," Media Infotama Journal, Vol. 8, No.2, 375-382, 2012.

[3] Kurniawan, R. A., Rochmad, M., and Puspita, E., "Coffee Maker Machine Based on Microcontroller 1-5," Final Project Journal. Department of Electronics Engineering, Electronics Engineering Polytechnic Institute Surabaya, 2011.

[4] Choir, Misbachul, "Design of Human-Machine Interface Application for Visualizing, Monitoring, and Controlling on Omron PLC," Final Project Report, Electrical Engineering Department, Universitas Muhammadiyah Malang, 2009. 
[5] Budiyanto, M., dan Wijaya, A., "Introduction to PLC," $1^{\text {st }}$ Edition. Gava Media, Yogyakarta, 2003.

[6] Putra, A. E., "PLC Concept, Programming and Application (Omron CPM1A/CPM2A and ZEN Programmable Relay)," $1^{\text {st }}$ Edition, Gava Media, Yogyakarta, 2007.

[7] Setiawan, I., "Programmable Logic Controller (PLC) and Technique of Control System Design," D. Hardjono, Ed., $1^{\text {st }}$ Edition, C.V Andi Offset, Yogyakarta, 2006.

[8] Winahyu, K. K., Triwiyatno, A., and Setiyono, B., "HMI (Human-Machine Interface) Design of Omron Nb7W-TwOOB on Plant Filtration Using Ultrafiltration Module," Transient, Vol. 4, No. 3, September 2015, ISSN: 2302-9927, 864, 2015.

[9] Manshur, M., Triwiyatno, A., and Setiyono, B. "Human Machine Interface (HMI) Design on Conveyor Model of Material Carrier," Transient, Vol. 4, No. 3, September 2015, ISSN: 23029927, 864. 2015.

[10] Tanojo Damaris, "Controlling Modular Production System Based on PLC Siemens S7-300 Using HMI Touch Panel," Calyptra: Students Scientific Journal of Universitas Surabaya, Vol. 4, No. 1, 2015.

[11] Erwin Nurdiansyah, Chasrun Hasani, and Amrul Faruq., "Application Monitoring Design of Water Tank Volume and Clarity System Using LabView NIMYRIO," Kinetik: Game Technology, Information System, Computer Network, Computing, Electronics, and Control, Vol. 2 No. 4, November, 2017. 